TITLE:

\title{
Memories of Toshisada Nishida
}

$\operatorname{AUTHOR}(S)$ :

Mitani, John C.

\section{CITATION:}

Mitani, John C.. Memories of Toshisada Nishida. Pan Africa News 2011, 18(special issue): 7-8

ISSUE DATE:

2011-09

URL:

http://hdl.handle.net/2433/147285

\section{RIGHT:}

Copyright (C) Pan Africa News. 
cussions we had everyday on chimpanzees. I was very curious about understanding differences in the behaviour between the two populations and we spent hours together passionately discussing leaf-grooming, tool use, social ranks and hunting strategies. Two passionate people discussing their passion through the long nightly hours!

\section{Tribute}

\section{Linda F. Marchant \\ Miami University, USA}

Professor Toshisada Nishida's research on the chimpanzees of the Mahale Mountains, Tanzania, first came to my attention in The Great Apes (1979) volume based on a Wenner-Gren Conference held in 1974. The quality and depth of his chapter included his ground-breaking insight into the social organization of Pan troglodytes. At that time I did not imagine that I would be so fortunate as to work with him on its sequel, Great Ape Societies (1996), based on another Wenner-Gren Conference held in 1994 and organized by Professor Nishida and Professor William McGrew. In the 20 years between those conferences and in the ensuing 17 years, Toshi produced a body of work that will stand as testimony to a consummate fieldworker.

In the last few years of his life, he had to cope with prolonged periods of illness but he persevered and completed his forthcoming book, Chimpanzees of the Lakeshore: Natural History and Culture at Mahale, Cambridge University Press, which will appear later this year. I had the privilege of reading several chapters of this book and in one of our e-mail exchanges I commented -

"Toshi, I had such pleasure in reading this chapter and many times I felt I was standing in Mahale watching 'your' chimpanzees as they live their remarkable lives. I especially enjoyed your stories of families, and sometimes I laughed out loud to read how perfectly you captured what it is like to be in a chimpanzee family."

On February 23rd 2011, he replied and said "...your words are very encouraging". He was racing against time to finish his book. I will miss Toshi, yet he will be with us, in this his final effort to share a lifetime of knowledge and love of the chimpanzees of the Mahale Mountains.

In the accompanying photo Toshi is with two of his favorite fellow 'alpha-males'-Frans de Waal and Bill McGrew! This was on the occasion of an International

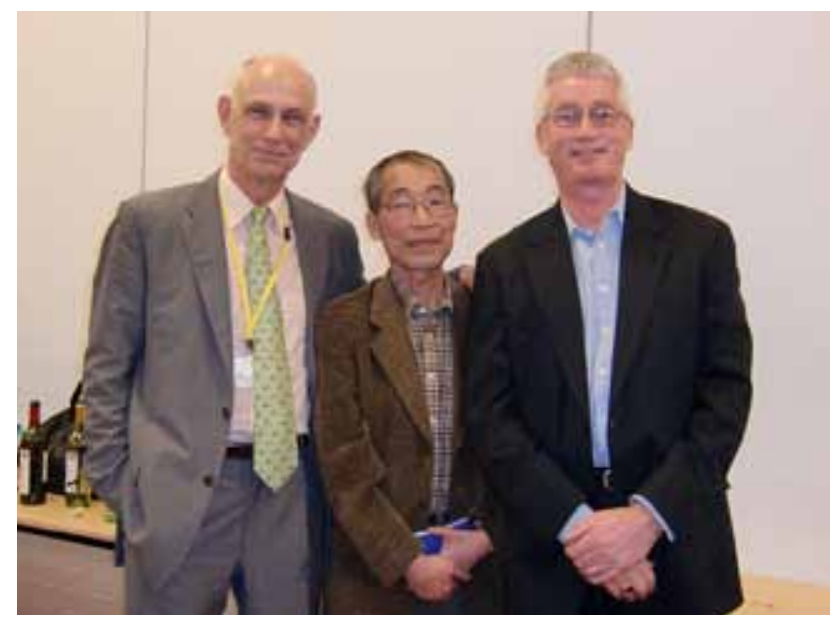

Symposium in March 2010, sponsored by "Hope-GM Lectures on Primate Mind and Society", organized by the Primate Research Institute under the direction of Professor Tetsuro Matsuzawa.

\section{Tribute}

\section{Richard W. Byrne \\ The University of St Andrews, Scotland, UK}

In 1980, Toshisada Nishida was visiting Bill McGrew at Stirling when there was a Scottish Primate Research Group event in St Andrews: so naturally both were invited, and the supper afterwards happened to be hosted at my house. I was excited to meet Dr Nishida, but a little disappointed that after being introduced he did not converse. (I knew nothing then about traditional Japanese etiquette.) At the next international conference we both attended, I was therefore slightly amazed when Dr Nishida enthusiastically greeted me with a sheaf of papers he had brought specially for my interest, thanking me for the wonderful hospitality in St Andrews! In the subsequent conversation, I asked very hesitantly whether it might ever be possible just to visit his chimpanzee field site ... and partly misunderstanding my words, Toshi gave me permission to carry out a research study at Mahale! By now, I was totally thrown, but very pleased: I had never even seen a wild ape at that point, and only studied one monkey species. Of course, I worked diligently in the next two years to come up with some ideas, and my wife Jen and I were able to work at Mahale in 1984 on chimpanzee vocalization. It may not have been the most successful project, but led to my subsequent career studying great apes: for which I am profoundly grateful. I never knew whether Toshi realised his early slip, but we remained good friends, meeting often at conferences. His death is a sad loss.

\section{Memories of Toshisada Nishida}

\author{
John C. Mitani \\ Michigan University, USA
}

"Here, let me fix this." Toshi eyed me suspiciously and quite warily as I began to dismantle the Honda generator at Kansyana camp. I had used the same kind of generator for many years in Borneo and knew how to repair them. I cleaned and fixed it quickly. Only later did Miya Hamai tell me that Toshi was more worried than I could have ever imagined. Apparently, there were old stories about how Itani sensei became upset over broken generators at Kabogo Point, the legendary site of his and Imanishi sensei's first effort to study wild chimpanzees along the shores of Lake Tanganyika.

Perhaps it was my ability to fix that generator during my first trip to Mahale that endeared me to Toshi. But I like to think there were other reasons. We both had an abiding passion for fieldwork, and came to respect each other for that. And while he came to trust me, I too trusted him unconditionally. In retrospect, some of that trust may have been misplaced. Like the time he convinced me to eat raw chicken in the field. He assured me that it 
would be alright. After all, chickens were raised in a special way for such consumption in Japan, where they were a delicacy. But I doubt that the chicken we ate that night in Kansyana camp was raised in the same way in Kasiha village!

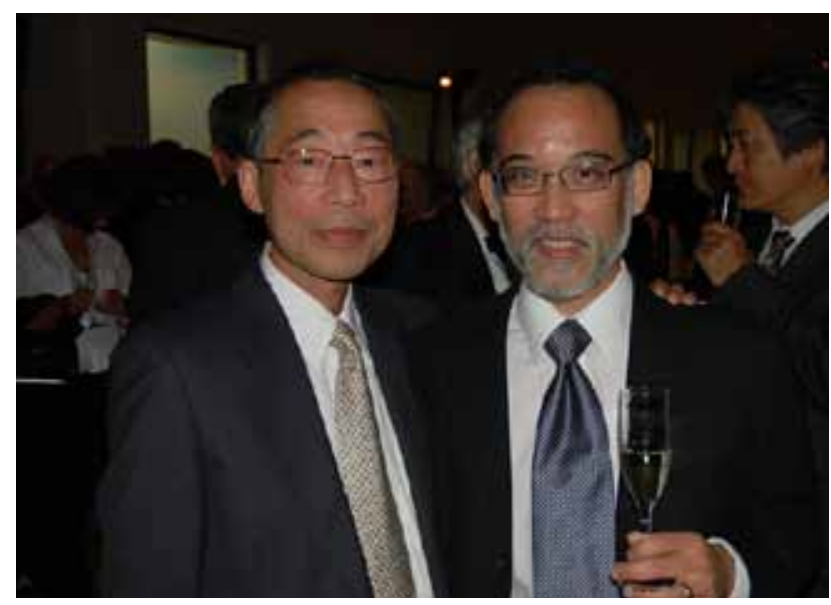

In the end, ours was a remarkable friendship. Those were in fact his last words to me in an email message he sent before he passed away. I wasn't aware at the time that this would be our last communication. Toshi was always quite stoic and never let on how much he must have been suffering, at least to me. I will remember his strength of character and the strength of our friendship, built on trust and mutual respect and admiration. I miss him greatly.

\section{A Memory of Toshisada Nishida}

\section{Craig Stanford \\ University of Southern California, USA}

I first met Toshisada Nishida in October 1991, when I visited him at his research camp in Mahale National Park. We had corresponded for some months and although I was relatively new in the chimpanzee research world, he graciously invited me to spend a week with him on a holiday from fieldwork at Gombe. To get to know him in the field and to tag along on his daily follows of the Mahale chimpanzees, with the team of assistants and students he had trained over the years, was truly awe-inspiring. One memorable wet day we sat watching the chimps doing a rain dance in a downpour so heavy I thought surely the hillside on which we sat would surely be washed away. Only when Dr. Nishida decided the weather would not allow further observations - by now streams of flood water were racing around our legs-did we return to camp. I learned that beyond his primatological wisdom, he knew which mushrooms were delicious and which were poisonous, and which fish from Lake Tanganyika made the best sushi.

Although I touched base with Dr. Nishida at the IPS Congress in Kyoto in 2010, not knowing he was ill at the time, my last vivid memory of him and his impact on our field is his retirement banquet and lecture, held in Kyoto in 2004. I was lucky enough to be among the group of foreign chimp-ologists invited to attend. We were treated royally. The highlight was observing the honorifics bestowed upon Dr. Nishida by so many hundreds of his aca- demic peers.

The world has lost one of the greatest primatologists in the history of our discipline. We must be grateful for his enormous contributions and for the legacy he leaves to future generations of both Japanese and western students of animal behavior.

\section{In Back of Nishida-san}

\section{Hiroshi Ihobe \\ Sugiyama Jogakuen University, Japan}

I am writing this tribute at Mahale. I first came here nine years ago in 1995 and stayed with Nishida-san for several months. I was fortunate to have been able to conduct research at field sites with three famous Japanese fieldworkers. When I was an undergraduate student, I followed Itani-san to Kuchinoshima Island in Japan to study feral cattle. As a graduate student, I went to Wamba in the former Zaire and walked with Kano-san in the forests there to study pygmy chimpanzees. And I spent time with Nishida-san at Mahale. Each field worker has his style. Itani-san wrote "Haiku" in the field and showed it to me while observing cattle. Kano-san did not speak to me often, and I only followed him from behind as we walked in the forest. Nishida-san recorded how chimpanzee foods tasted by eating them. I think Itani-san and Kanosan were generalists and Nishida-san was a specialist. Nishida-san's interest was focused entirely on chimpanzees. He seemed to try to understand the environment through the eyes of the chimpanzees. All three fieldworkers, however, have common features. They did not teach me many things directly. Instead, I learned the way to conduct fieldwork by following them in the field. While following them, I observed their manners and experienced how to carry out fieldwork successfully. While I followed Nishida-san, I came to learn many important things about Mahale. His death has left a deep hole and is a big loss for Japanese primatology. I wish I could follow him from behind to Mahale once more because I still have to learn many things about there and about fieldwork. This, however, is an impossible dream for now. I can honor his soul by working hard to emulate him in the field, but it is too hard to equal him when it comes to fieldwork.

\section{Short Tribute}

\author{
Miho Nakamura \\ ANC Productions Inc./Kyoto Unviersity, Japan
}

Remember, he was speaking fast about the classification of Hominidae in the first class of primatology, I was just 20 years old then. Remember, he took a picture of a Japanese macaque showing threat while I was provoking the female, then I realized how much I get excited in the field. Remember, we climbed a cliff of the Mahale mountains only to discover a breathtaking view. We couldn't catch up the chimpanzees but he looked happy and satisfied with the view. Dr. Nishida, always young in spirit, loves to visit a new place as well as deepening his scientific knowledge. 